\title{
Pemantauan Kualitas Udara Terintegrasi dengan Semantic Web Of Thing
}

\author{
M. Udin Harun Al Rasyid ${ }^{1}$, Rengga Asmara ${ }^{2 *}$, Hendi Yanuar Setianto ${ }^{3}$ \\ 1,2,3 Departemen Teknik Informatika dan Komputer; Politeknik Elektronika Negeri Surabaya; \\ Kampus PENS, Jalan Raya ITS, Keputih, Sukolilo, Surabaya; Telp. +62 31594 7280, Fax +62 \\ 31594 6114; e-mail: udinharun@pens.ac.id, rengga@pens.ac.id, hendiyanuar@gmail.com
}

Korespondensi email: rengga@pens.ac.id

Diterima: 27 April 2020 ; Review: 5 Mei 2020; Disetujui: 29 Mei 2020

Cara sitasi: Al Rasyid MUH, Asmara R, Setianto HY. 2020. Pemantauan Kualitas Udara Terintegrasi dengan Semantic Web of Thing. Informatics for Educators and Professionals. Vol 4 (2): 153-162.

Abstrak: Udara merupakan salah satu sumber daya alam yang paling penting bagi keberadaan makhluk hidup di bumi ini. Semua organisme hidup membutuhkan kualitas udara yang baik bebas dari gas berbahaya untuk melanjutkan hidup mereka. Beberapa organisasi telah membuat sistem monitoring dengan struktur data yang berbeda tanpa adanya standar penyamaan. Di sisi lain, manusia masih membutuhkan waktu untuk menafsirkan data-data sensor untuk mendapatkan informasi. Linked Data merupakan metode untuk merepresentasikan dan menghubungkan data terstruktur pada web. Data terstruktur tersebut diintegrasikan dengan Semantic Sensor Web (SSW) yang dipublikasikan pada beberapa format sehingga mudah dibaca mesin dan dapat dihubungkan ke data terstruktur lainnya. Kemudian, untuk menyajikan data yang aktual, sistem monitoring didesain untuk menerima data secara terus-menerus, diquery secara real-time dan dibagikan melalui sosial media.

Kata kunci: Linked Data, Pemantauan Kualitas Udara, Semantic Web, Sosial Media.

Abstract: Air is one of the most essential natural resources for the existence and survival of the entire life on this planet. all living organisms need good quality of air which is free of harmful gases to continue their life. Some organizations have set up monitoring systems with different data structures without an equalization standard. On the other hand, humans still need time to interpret sensor data to get information. Linked Data is a method for representing and connecting structured data on the web. The structured data is integrated with the Semantic Sensor Web (SSW) which is published in several formats so that it is easy to read and can be connected to other structured data. Then, to present the actual data, the monitoring system is designed to receive data continuously, queried in real time and shared through social media

Keywords: Air Quality Monitoring, Linked Data, Semantic Web, Social Media

\section{Pendahuluan}

Udara merupakan salah satu sumberdaya alam yang paling penting bagi keberadaan makhluk hidup di bumi ini. Semua bentuk kehidupan termasuk tumbuhan dan hewan bergantung pada udara. Dengan demikian, semua organisme hidup membutuhkan kualitas udara yang baik bebas dari gas berbahaya untuk melanjutkan hidup mereka. Menurut World's Worst Polluted Places oleh Blacksmith Institute pada tahun 2008[1]. Dua masalah polusi terburuk di dunia adalah kualitas udara perkotaan dan polusi udara dalam ruangan. Polusi udara yang mayoritas didominasi oleh emisi gas CO (Carbon Monoxida) dan Partikel gas PM 2.5 hal ini disebabkan oleh populasi yang terus meningkat, mobil dan industrinya mencemari semua udara dengan kecepatan yang mengkhawatirkan. Polusi udara dapat menyebabkan efek kesehatan jangka panjang dan jangka pendek. Ditemukan bahwa orang tua dan anak-anak muda lebih dipengaruhi oleh polusi udara. Efek kesehatan jangka pendek termasuk iritasi mata, 
hidung, dan tenggorokan, sakit kepala, reaksi alergi, dan infeksi saluran pernapasan bagian atas. Beberapa efek kesehatan jangka panjang adalah kanker paru-paru, kerusakan otak, kerusakan hati, kerusakan ginjal, penyakit jantung, dan penyakit pernapasan. Efek negatif lain dari polusi udara adalah pembentukan hujan asam, yang merusak pohon, tanah, sungai, dan satwa liar. Beberapa efek lingkungan lain dari polusi udara adalah kabut, eutrofikasi, dan perubahan iklim global. Oleh karena itu, polusi udara adalah salah satu kekhawatiran paling mengkhawatirkan bagi kita saat ini. Mengatasi kekhawatiran ini, orang telah menghabiskan banyak upaya penelitian dalam evaluasi dan pemantauan kualitas udara. Dalam beberapa dekade terakhir, banyak peneliti telah menghabiskan banyak waktu untuk mempelajari dan mengembangkan berbagai model dan metode dalam analisis dan evaluasi kualitas udara[2].

Semantic Web merupakan teknologi web generasi baru yang memberikan perubahan besar pada World Wide Web. Semantic Web adalah web of data. Pada Web 3.0, web tidak lagi hanya terbatas sebagai sebuah dokumen yang mengandung informasi dan link-link yang digunakan pengunjung untuk mengakses dokumen yang lain (Web 1.0). Semantic Web tidak hanya sebagai sebuah aplikasi yang mampu mengolah dan memproses data, menerima input dari user, dan mempublikasikan data (Web 2.0). Akan tetapi, Semantic Web mampu mengombinasikan dan merelasikan data-data pada domain yang berbeda secara mudah dan dapat diakses, dicari, dan dibagikan[3].

Jika dibandingkan teknologi Web 1.0, Web 2.0, dan Web 3.0 memiliki beberapa perbedaan. Tabel 1. dibawah ini menunjukkan perbedaan antara Web 1.0, Web 2.0, dan Web 3.0[4].

Tabel 1. Perbedaan teknologi Web 1.0, Web 2.0 dan Web 3.0

\begin{tabular}{|c|c|c|}
\hline Web 1.0 & Web 2.0 & Web 3.0 \\
\hline Web & Sosial Web & Semantic Web \\
\hline Baca saja & Baca dan tulis & Baca, Tulis dan jalankan web \\
\hline Sharing Informasi & Interaksi & Immersion \\
\hline Hubungkan informasi & Hubungkan orang & Hubungkan pengetahuan \\
\hline $\begin{array}{l}\text { Di Web 1.0, mesin pencari } \\
\text { mengambil konten makro. Pencarian } \\
\text { sangat cepat tetapi seringkali } \\
\text { hasilnya tidak akurat atau lebih dari } \\
\text { yang bisa dikunyah oleh pengguna. }\end{array}$ & $\begin{array}{l}\text { Di Web 2.0, mesin pencari } \\
\text { mengambil tag dengan konten mikro. } \\
\text { Proses penandaan adalah manual, } \\
\text { membosankan dan mencakup persen } \\
\text { yang dapat diabaikan dari WWW. } \\
\text { Web } 2.0 \text { menandai semuanya: } \\
\text { gambar, tautan, acara, berita, Blog, } \\
\text { audio, video, dan sebagainya. Google } \\
\text { Base bahkan mengambil teks konten } \\
\text { mikro. }\end{array}$ & $\begin{array}{l}\text { Di Web 3.0, mesin pencari } \\
\text { diharapkan akan mengambil teks } \\
\text { konten mikro yang ditandai secara } \\
\text { otomatis. Ini berarti menerjemahkan } \\
\text { miliaran konten makro Web } 1.0 \text { ke } \\
\text { dalam konten mikro. Hasilnya bisa } \\
\text { pencarian yang lebih tepat karena } \\
\text { penandaan dapat memecahkan } \\
\text { bagian dari ambiguitas yang } \\
\text { diperkenalkan homonim dan sinonim } \\
\text { ke dalam proses pencarian. }\end{array}$ \\
\hline $\begin{array}{l}\text { Web } 1.0 \text { adalah semua tentang } \\
\text { konten statis, penerbitan konten satu } \\
\text { arah tanpa interaksi nyata antara } \\
\text { pembaca atau penerbit atau satu } \\
\text { sama lain. }\end{array}$ & $\begin{array}{l}\text { Web } 2.0 \text { lebih tentang komunikasi } 2 \\
\text { arah melalui jejaring sosial, blogging, } \\
\text { wiki, penandaan, konten dan video } \\
\text { yang dibuat pengguna. }\end{array}$ & $\begin{array}{l}\text { Web } 3.0 \text { tidak dapat ditentukan. Al } \\
\text { dan web mempelajari apa yang Anda } \\
\text { inginkan dan memberikan Anda } \\
\text { pengalaman web yang } \\
\text { dipersonalisasi. Dimasa depan } \\
\text { dimungkinkan web lebih interaktif } \\
\text { dengan pengguna, yang mengarah } \\
\text { ke semacam kecerdasan buatan web } \\
3.0\end{array}$ \\
\hline
\end{tabular}

Sumber: (D. Naik, Umesha, 2014)

Pada perkembangan selanjutnya, manusia membutuhkan data-data terstruktur perlu untuk dihubungkan dengan data-data yang berasal dari lingkungan secara nyata, seperti data sensor. Data sensor dibutuhkan untuk mendapatkan informasi tentang kondisi linkungan secara terupdate. Namun, manusia masih membutuhkan waktu untuk menafsirkan data-data sensor untuk mendapatkan informasi. Maka, data-data tersebut harus saling dikaitkan sehingga memudahkan manusia dalam mengambil informasi dari data-data tersebut. Metode untuk mengaitkan data-data tersebut adalah Linked Data yang ditambahkan data sensor atau disebut sebagai Linked Sensor Data.

Semantik Sensor Web (SSW) adalah kombinasi dari jaringan sensor, layanan web, database dan teknologi web semantik. Data-data yang didapatkan dari sensor-sensor yang disebarkan di berbagai titik lokasi diolah sedemikian rupa dengan menggunakan Linked Data 
pada Semantic Web sehingga mampu menghasilkan data dengan representasi pengetahuan. Sensor data dianotasikan dengan semantic metadata untuk meningkatkan interoperabilitas serta penyediaan informasi penting[5]. Secara khusus, SSW menambahkan informasi pada data yang didapat dari sensor dengan semantic metadata spasial, temporal, dan tematik[6]. Metode yang digunakan untuk membangun Semantik Web adalah menghubungkan data sensor yang tersebar dengan memanfaatkan layanan API dari sensor server web semantik saling berhubungan. Selanjutnya, data diambil dari sensor yang diwakili dalam bentuk ontologi dengan jenis RDF / OWL dan disimpan dalam RDF Repository (OPENRDF-SESAME) untuk diproses dan dipublikasikan ke layanan web semantik. SPARQL library dan Curl berfungsi untuk menjembatani antara Service web dan Apache Tomcat. Data yang ada di file RDF TripleStore akan ditampilkan kepada pengguna untuk memanfaatkan layanan menggunakan standart RESTFUL API. Maka data yang ada di database RDF dapat ditampilkan dalam format data JSON[7].

Semantic Web of Things (SWoT) adalah perpaduan dari tren loT dengan teknologi web melalui protokol CoAP[8]. CoAP adalah standar terbuka untuk membangun layanan Web RESTful yang tertanam yang dioptimalkan untuk perangkat terbatas seperti yang terletak di penyebaran IoT. SWoT menjanjikan koneksi tanpa batas ke loT yang memungkinkan integrasi dunia fisik dan digital dengan konsep sharing dan re-use. Visi SWoT adalah memungkinkan sistem berbasis pengetahuan yang secara otonom untuk penyimpanan, pencarian, manajemen informasi dan menyediakan akses secara transparan di area tertentu.

Wireless Sensor Network adalah jaringan komunikasi sensor wireless network yang terdiri dari sensor-sensor otomatis yang terdistribusi secara spasial. Jaringan tersebut digunakan untuk memantau kondisi fisik maupun kondisi lingkungan, seperti temperatur, tekanan, polusi, dan lainnya[9]. Salah satu implementasi WSN secara besar-besaran dalam kehidupan nyata yakni digunakan untuk memantau kondisi kualitas udara. Environmental Protection Agencies (EPAs) dari beberapa negara di dunia telah bekerjasama membangun sistem pemantauan kondisi kualitas udara dan telah mencakup 800 kota di 70 negara. Datadata sensor dari sistem monitoring tersebut dapat dilihat secara terbuka melalui website http://aqicn.org.

Beberapa organisasi telah membuat sistem monitoring kualitas udara sendiri. Organisasiorganisasi tersebut tentunya telah membuat struktur data yang berbeda tanpa adanya standar penyamaan. Apabila data-data sensor tersebut bisa diakses dari satu tempat, maka pemantauan dan kontrol akan lebih mudah. Oleh karena itu, perlu adanya sistem yang dapat menyatukan data-data sensor ini dan dapat dimaintain secara mudah. Selain itu, untuk menyajikan informasi yang lebih bermanfaat, data-data dari sensor gas tersebut dapat ditambahkan dengan data lingkungan dan kesehatan. Dengan Linked Sensor Data, data-data sensor dapat saling digabungkan dan direlasikan dengan data pada domain lingkungan dan kesehatan sehingga dapat disajikan dalam bentuk informasi yang lebih informatif[10].

Dalam penelitian ini, akan diusulkan satu solusi untuk memaksimalkan pemberian informasi kualitas udara kepada masyarakat menggunakan aplikasi messenger Telegram. Masyarakat bisa berkomunikasi dengan Bot Telegram yang akan dirancang sedemikian rupa agar dapat memberikan informasi kualitas udara. Aplikasi Telegram dipilih karena aplikasi ini gratis, ringan dan multiplatform. Telegram juga memiliki Bot API yang cukup lengkap dan makin berkembang, sehingga memungkinkan untuk membuat Bot pintar yang dapat merespon pesan dari masyarakat.

\section{Metode Penelitian}

Indeks Kualitas Udara (bahasa Inggris: Air Quality Index, disingkat AQI) adalah ukuran yang digunakan pemerintah untuk menyatakan tingkat polusi udara saat ini atau memperkirakan tingkat polusi udara dimasa mendatang. Setiap negara memiliki indeksnya masing-masing, berdasarkan standar kualitas udara di negaranya. Standar indeks yang akan digunakan pada penelitian ini menggunakan standar US EPA. Perhitungan AQI berdasarkan standar US EPA menggunakan rumus 1[11]: 


$$
I=\frac{I_{\text {high }}-I_{\text {low }}}{C_{\text {high }}-C_{\text {low }}}\left(C-C_{\text {low }}\right)+I_{\text {low }}
$$

Keterangan:

$\begin{array}{ll}\text { I } & =\text { Indeks kualitas udara } \\ \text { C } & =\text { konsentrasi polutan } \\ \text { C low } & =\text { breakpoint konsentrasi dimana kurang dari C } \\ \text { C high } & =\text { breakpoint konsentrasi dimana kurang dari C } \\ \text { I low } & =\text { breakpoint indeks berdasarkan C low } \\ \text { I high } & =\text { breakpoint indeks berdasarkan C high }\end{array}$

Data breakpoint EPA dapat dilihat secara langsung di website https://aqs.epa.gov/aqsweb/documents/codetables/aqi_breakpoints.html.

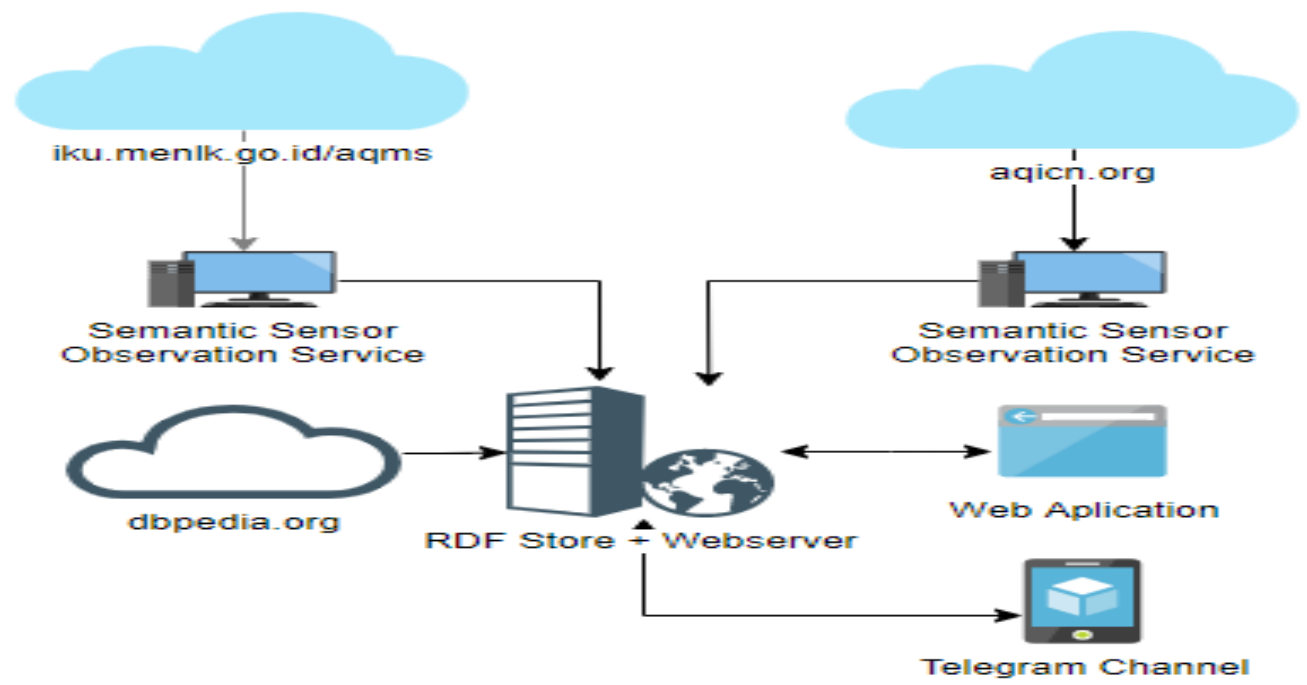

Sumber: Hasil Penelitian (2020)

Gambar 1. Rancangan diagram sistem

Pada Gambar 1. adalah rancangan sistem yang akan dibangun dengan penjelasan sistem berikut: 1) Data Sensor Gas, Data sensor gas yang biasa dijadikan sebagai parameter kualitas udara adalah partikel $\mathrm{CO}, \mathrm{NO} 2, \mathrm{SO} 2, \mathrm{O} 3, \mathrm{PM} 10$, dan PM2. 5 data tersebut bisa didapatkan dari pemasangan sensor secara mandiri maupun hasil pengambilan dari website monitoring kualitas udara yang sudah ada seperti http://aqicn.org, https://airnow.gov/, http://iku.menlhk.go.id/, dll. Setiap website memiliki standar yang sama untuk menentukan nilai AQI (Air Quality Index); 2) Semantic Sensor Observation Service, Data yang didapat baik dari sensor nyata maupun dari web lain diolah agar menjadi Linked Sensor Data.

Tujuan utama dari service ini adalah menambahkan metadata pada data-data sensor. Selanjutnya, penafsiran data dapat dilakukan dengan memanfaatkan metadata-metadata tersebut. Beberapa proses yang dilakukan pada bagian ini: a) Konversi data sensor ke bentuk RDF/XML, b) Menambahkan metadata pada data RDF/XML dengan menggunaan Semantic Rule, c) Mengirim data RDF/XML ke RDF Store. 3) RDF Store merupakan layanan untuk penyimpanan Linked Data. Biasanya RDF Store juga disertai dengan layanan untuk melakukan query SPARQL yang biasa disebut dengan SPARQL Endpoint. Hasil query yang ditampilkan pada SPARQL Endpoint dapat berupa tabel HTML, Json, dan Turtle. Selain dari SPARQL Endpoint, query juga dapat dilakukan dengan mengirimkan query melewati HTTP Request. Pada penelitian ini, RDF Store yang digunakan adalah Apache Jena Fuseki. Fuseki server telah dilengkapi dengan SPARQL Endpoint service. 4) Aplikasi web mengambil data yang disimpan pada RDF Store. Query SPARQL dila dilakukan dengan mengirim request ke RDF Store. Query string dikirimkan sebagai variabel query menggunakan metode GET ke SPARQL endpoint. 
Data yang didapatkan dari request tersebut dapat berupa $\mathrm{xml}, \mathrm{csv}$, json, dan text sesuai dengan variabel format yang juga dikirim dengan metode GET.

Dengan demikian, SPARQL Endpoint menjadi interface antara RDF Store dan aplikasi. Query yang dikirim ketika aplikasi web pertama kali dibuka berbeda dengan query yang dikirim setelahnya. Pada saat pertama kali web dibuka, query yang dikirim tidak difilter untuk mendapatkan data terbaru sehingga jumlah data yang didapat banyak. Ketika terdapat data RDF yang baru saja dikirim ke RDF Store, maka aplikasi web juga akan menerima data abstrak dari data RDF tersebut. Maksud dari abstrak yakni, bukan data keseluruhan akan tetapi hanya data yang berisi atribut-atribut yang menjadi wakil dari data RDF yang sebenarnya. Isi dari data abstrak tersebut yakni nilai AQI, nama sumber data, dan lokasi. Kemudian query dilakukan dengan filtering berdasarkan nilai atribut-atribut tersebut. Hal itu dilakukan untuk mendapatkan metadata yang merupakan penafsiran dari data tersebut.

Pada penelitian ini, RDF Store yang digunakan adalah Apache Jena Fuseki. Query yang diterapkan yakni query SPARQL yang melalui HTTP. Query tersebut dijalankan dari file javascript yang berisi package socket.io. SPARQL Query yang dikirim melalui HTTP sedikit berbeda dengan query yang dijalankan langsung melalui SPARQL Endpoint. Query string yang dikirim lewat HTTP tidak bisa menggunakan Prefix URI sehingga terlihat lebih panjang daripada query string yang dijalankan langsung di SPARQL Endpoint. Ditambah lagi, query string perlu diubah ke URL encoding sebelum dikirimkan. 5) Publikasi di sosial media, Seiring semakin majunya teknologi informasi dan komunikasi, penyampaian pesan tidak lagi hanya dijalankan secara tatap muka, melalui website namun dapat pula melalui media sosial yang dinilai lebih efektif dan efisien untuk digunakan. Salah satunya melalui media sosial Telegram yang memungkinkan penggunanya membuat Bot untuk menyampaikan pesan secara realtime, bersamaan dan terus menerus.

Desain keterhubungan antar entitas pada ontology mencakup beberapa hal yakni Class, Object Properties, Annotation properties, Datatype, Data properties, dan Individual. Class biasa digunakan untuk mewakili sebuah entitas. Setiap entitas dapat memiliki atribut berupa entitas lain maupun sebuah nilai. Entitas yang memiliki atribut entitas dapat dihubungkan menggunakan Object Properties. Sedangkan untuk menghubungkan entitas dengan atribut yang berisi nilai dapat menggunakan Data Properties.

Setiap Data Properties memiliki tipe data, dimana tipe data pada ontology direpresentasikan dengan Datatype. Annotation Properties digunakan untuk memberikan anotasi tambahan pada entitas, seperti label, komentar, versi, dan lainnya. Terakhir, ontology juga dapat mengandung individu, dimana setiap individu merupakan data yang telah dimodelkan dengan desain ontology tersebut.

Desain ontology mencakup dua hal yakni desain keterhubungan antar entitas dan desain rule. Tool yang bisa digunakan secara gratis untuk merancang ontology yaitu Protege. Protege telah menyediakan beberapa plugin tambahan untuk mendukung desain ontology. Output dari desain ontology ini yakni sebuah file berekstensi ${ }^{*}$.owl yang ditulis dengan format XML.
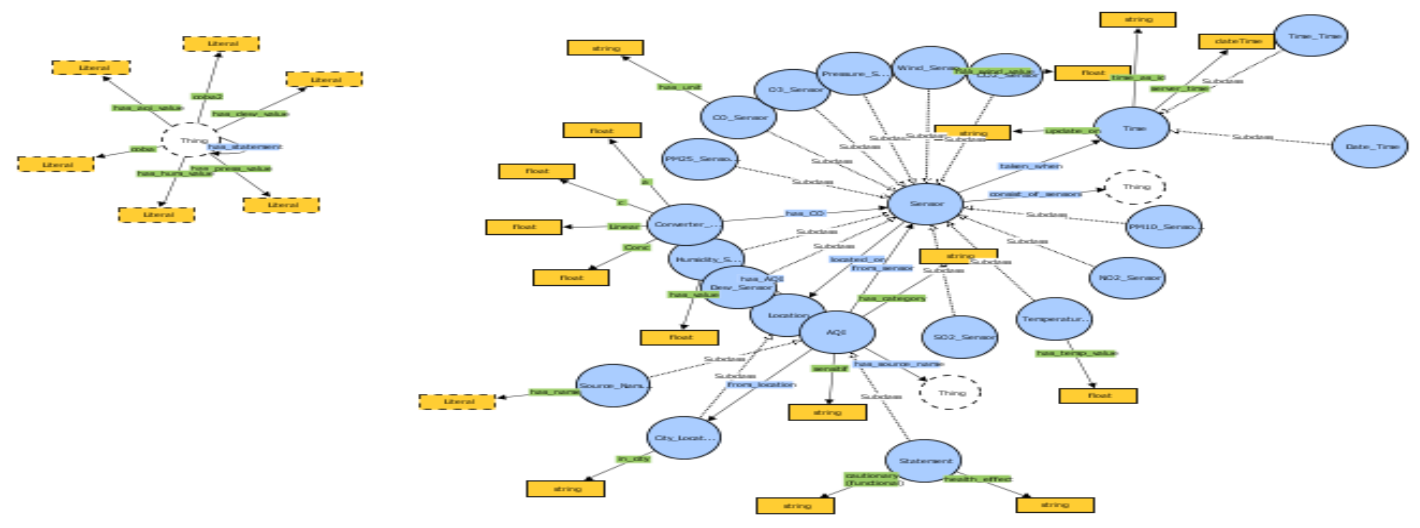

Sumber: Hasil Penelitian (2020)

Gambar 2. Desain ontology ditampilkan menggunakan aplikasi VOWL

Gambar 2. adalah desain ontology yang dibuat pada penelitian ini, pemodelan rule pada ontology dapat menggunakan bahasa pemodelan Semantic Web Rule Language (SWRL). 
Penulisan SWRL mirip seperti pemrograman prolog. Rule ini digunakan pada saat reasoning dilakukan untuk menambahkan metadata.

Rule yang dibuat mengacu pada ketentuan US EPA, dimana setiap nilai AQI memiliki kategori tingkat urgensitas. Tingkat urgensitas tersebut terbagi menjadi enam: Normal, Moderate, Unhealthy for Sensitive Groups, Unhealthy, Very Unhealthy, dan Hazardous. Kemudian, setiap polutan memiliki dampak yang lebih khusus pada beberapa orang tertentu seperti kalangan anak-anak, dewasa, atau orang yang memiliki penyakit tertentu seperti asma. Data dampak yang lebih khusus ini juga didapatkan dari ketetapan yang sudah disusun US EPA.

\section{Hasil dan Pembahasan}

Web scrapping dilakukan dengan menggunakan library HTML-Unit pada Java. Scrapping dilakukan secara periodik. Data yang diambil hanya data-data penting yaitu nama lokasi, waktu publikasi data, nilai AQI dan nama tiap polutan. Khusus untuk scrapping pada website iku.menlhk.go.id, karena memiliki nama ISPU maka diambil juga. Data-data yang diambil disimpan pada sebuah file dengan format json.

Data-data sensor yang telah diubah ke bentuk JSON, dikonversi menjadi data RDF. Hasil output data RDF tentu saja akan menyesuaikan dengan pemodelan ontology yang sudah dibuat. Mapping data terdiri dari dua tahapan. Tahap pertama, data JSON diubah ke bentuk RDF tanpa dilakukan reasoning. Setelah data RDF terbuat, penambahan metadata atau reasoning baru bisa dilakukan yakni dengan menggunakan Semantic Rule yang sudah dibuat. Hasil akhir dari mapping data ini adalah data dengan format RDF/XML. Kemudian data tersebut dikirimkan ke RDF Store untuk disimpan.

\subsection{Aplikasi Web}

Sebelum aplikasi web dibuat, hal yang perlu diketahui adalah bagaimana aplikasi web dapat mengakses data-data yang tersimpan di RDF Store. Cara yang paling awal adalah dengan mengakses SPARQL endpoint dan menguji hasil query SPARQL.

Output query SPARQL yang dijalankan pada SPARQL endpoint dari Fuseki bisa berupa format data csv, json, maupun tabel HTML. Apabila syntax query yang dituliskan benar, maka output data akan tampil, jika salah maka SPARQL endpoint akan menampilkan error. Hal tersebut sangat berguna untuk memastikan apakah query yang ditulis sudah benar atau belum. Selanjutnya, barulah pengujian query melalui HTTP dilakukan.

Representasi data juga masih sederhana berupa peta dan tabel yang berisi: waktu, sumber data, lokasi, nilai AQI, kategori AQI, dan keterangan-keterangan yang merupakan hasil reasoning. Keterangan-keterangan tersebut berisi statement, cautionary, dan health message.

Validasi hasil reasoning dapat dilakukan dengan mencocokkan data yang tersimpan pada RDF Triple Store dengan rule yang dibuat. Data yang tersimpan pada RDF Triple Store dapat diakses dengan melakukan query pada SPARQL Endpoint. Apache Jena Fuseki telah menyediakan protokol untuk pembacaan data secara keseluruhan dengan format Turtle. Data ditampilkan berupa triple yakni subject, object, dan predicate.

\section{$\mathrm{RAQM}$}

Realtime Air Quality Monitoring System

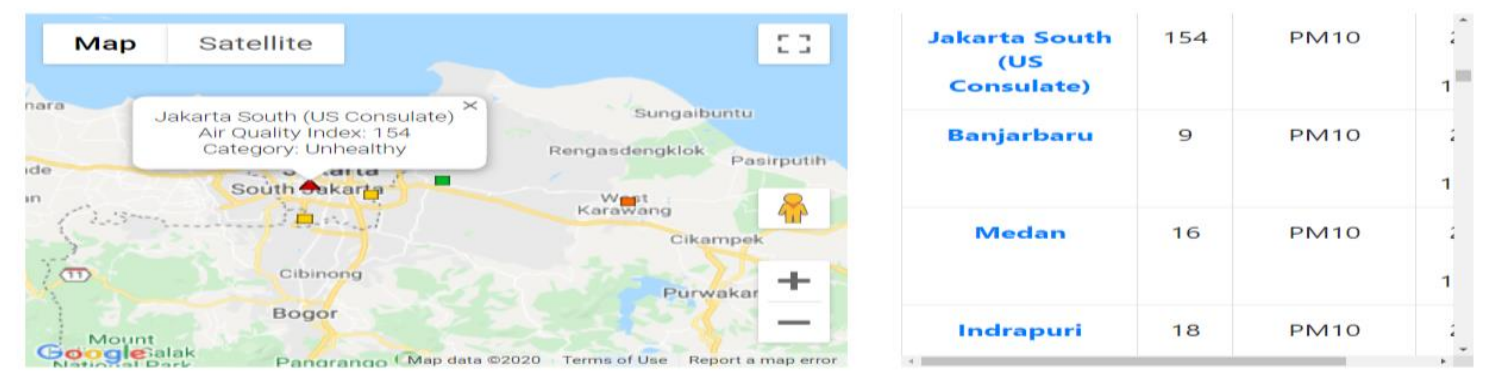

Sumber: www.iku.menlhk.go.id/aqms

Gambar 3. Data ditampilkan secara real-time pada laman web 
Gambar 3. menunjukkan nilai AQI 154 dari polutan PM10 yang merupakan hasil scrapping dari website AQICN pada lokasi Jakarta Selatan, artinya nilai AQI tersebut tergolong pada kategori Unhealhty. Selanjutnya, nilai tersebut memiliki makna berupa Cautionary health effect: Peningkatan gejala pernafasan dan pemburukan penyakit paru-paru, seperti asma; kemungkinan efek pernapasan pada populasi umum.

Beberapa kota besar memiliki data lengkap pada ke-enam sensornya, misalnya kota London yang memiliki nilai AQI terbesar 37 berdasarkan nilai polutan PM2.5, nilai AQI 12 berdasarkan nilai polutan PM10, nilai AQI 18 berdasarkan polutan O3, nilai AQI 2 berdasarkan polutan SO2, nilai AQI 3 berdasarkan polutan NO2, nilai AQI 7 berdasarkan polutan $\mathrm{CO}$. Semua nilai AQI tersebut tergolong Good dengan Cautionary health effect: Orang dengan penyakit pernapasan atau jantung, orang tua dan anak-anak adalah kelompok yang paling berisiko.

Di beberapa kota yang pada website $A Q I C N$ ditambahkan huruf asli dari negara tersebut (misalnya: huruf Kanji, Arab, Cina, Rusia, Thailand, Korea, dll) dapat diambil datanya akan tetapi data tersebut belum berhasil ditampilkan melalui peta hanya sebatas tabel saja. Sebagai contoh kota Seoul (서울) yang memiliki nilai $A Q I 42$ dari polutan NO2. Nilai $A Q I$ tersebut tergolong Good dengan Cautionary health effect: paling beresiko kepada anak-anak dan orang dengan asma, atau penyakit pernapasan lainnya.

Seperti Gambar 4. beberapa kota besar di Indonesia memiliki 2 nilai AQI. Sebagai contohnya, Kota Jambi menurut data dari website aqicn.org mempunyai nilai AQI 13 sedangkan menurut data website www.iku.menlhk.go.id/agms mempunyai nilai AQI 16. Hal ini mungkin disebabkan oleh lokasi letak sensor yang berbeda walaupun keduanya memiliki arti nilai AQI Good dengan Cautionary health effect: orang dengan penyakit pernapasan adalah kelompok yang paling beresiko.

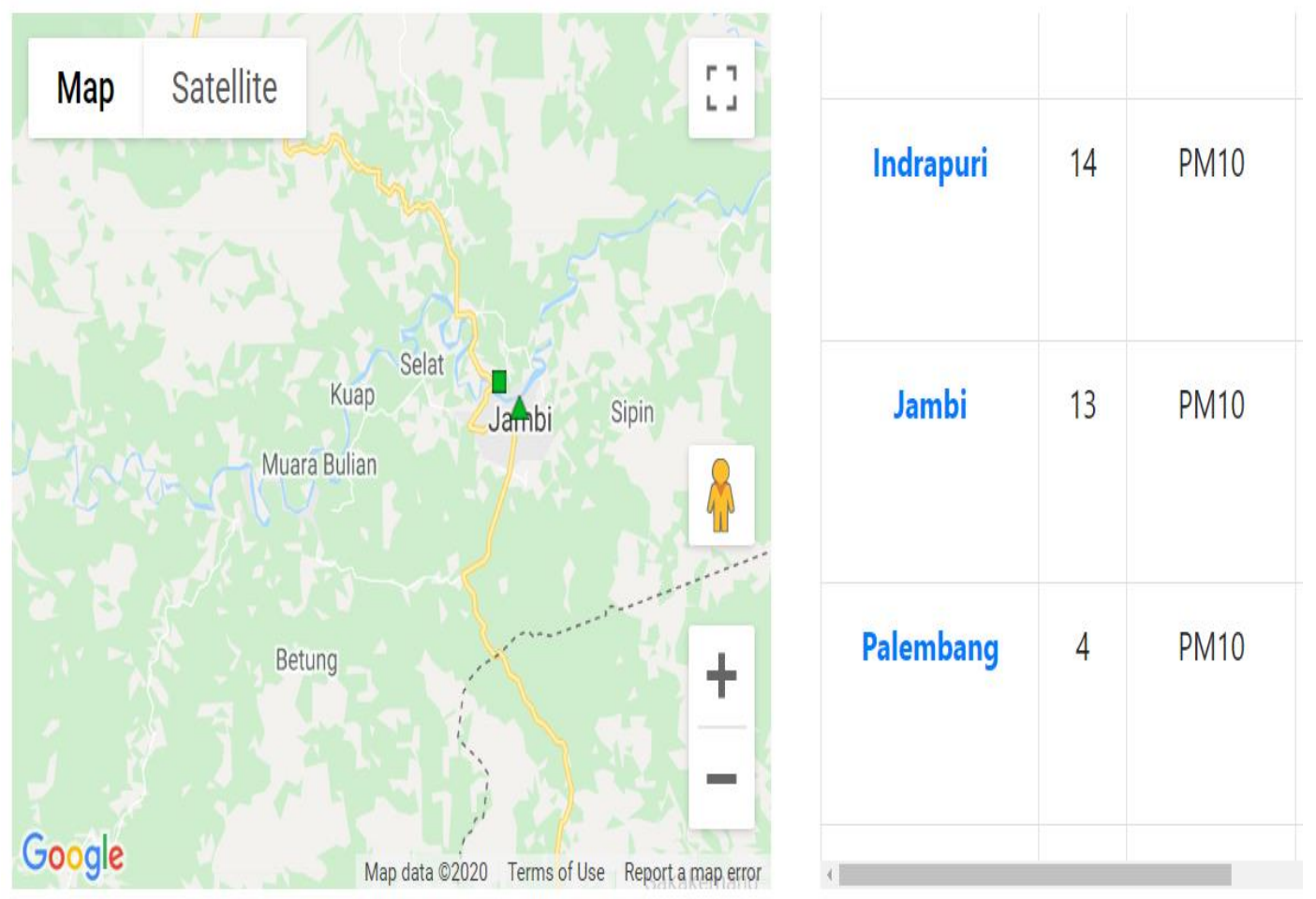

Sumber: $\underline{\text { www.iku.menlhk.go.id/agms }}$

Gambar 4. Salah satu contoh kota yang memiliki 2 Nilai AQI 


\subsection{Telegram Bot}

Telegram API memungkinkan siapa saja untuk membuat bot yang akan membalas semua penggunanya jika mengirimkan pesan perintah yang bisa diterima oleh Bot tersebut. Layanan ini hanya tersedia bagi pengguna yang menggunakan aplikasi Telegram saja. Sehingga pengguna yang ingin menggunakan Bot harus terlebih dahulu memiliki akun Telegram. Pembuatan telegram bot pada penelitian ini bertujuan untuk mempermudah dalam menyampaikan data dari aplikasi kepada masyarakat luas yang telah memiliki akun Telegram dan tergabung kedalam channel.

Bot Telegram dapat melakukan apa saja sesuai perintah (yang sudah tersedia). Bot telegram bisa digunakan untuk melakukan pencarian, sebagai penghubung, pengingat, pengajar, pengintegrasi, dan lainnya.

Untuk berinteraksi melalui Telegram Bot diperlukan sebuah webhook. Webhook atau yang biasa disebut callback adalah cara bagi suatu aplikasi untuk menyediakan aplikasi lain dengan informasi real-time. Lebih mudahnya, webhook adalah link URL yang ditambahkan agar data yang dikirim dapat langsung diterima di waktu sama dengan link URL yang sudah ditentukan.

Pembuatan Bot Telegram memerlukan registrasi bot yang dilakukan BotFather account untuk nama bot dan mendapatkan API key. API key digunakan pada setiap request API ke telegram server. Semua command yang diperlukan juga didaftarkan di BotFather. Telegram bot pada penelitian ini memiliki beberapa command/perintah diantaranya sebagai berikut:

/start-Memulai pengiriman otomatis status AQI.

/change - Mengubah nama kota yang dipantau status AQInya.

laqi-Menampilkan status AQI berdasarkan inputan.

/status - Menampilkan status AQI dari daerah yang telah di setting.

/list - Menampilkan 15 kota terupdate nilai AQInya.

lend-Menghentikan pengiriman otomatis status AQI.

/help - Menampilkan semua perintah.

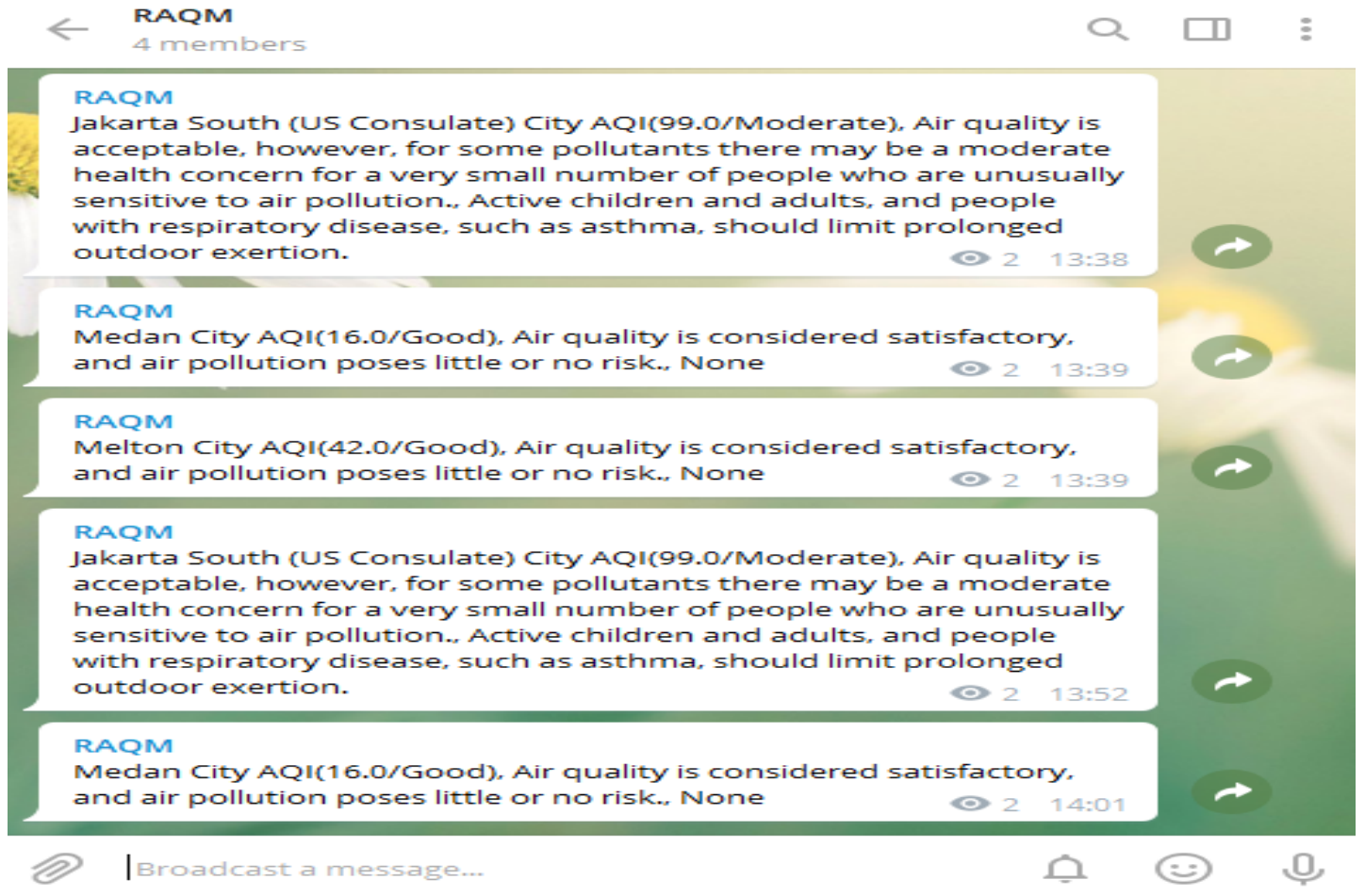

Sumber: Telegram API (2020)

Gambar 5. Pesan yang dikirim oleh Bot ke telegram channel 
Pada Gambar 5. menunjukkan hasil dari fungsi /start yang langsung mengirimkan status dari 3 kota sekaligus dan akan diulang tiap 1 jam sekali secara otomatis.

Dengan mengetik perintah /start maka bot ini akan mengirimkan status kota tertentu tiap 1 jam sekali secara otomatis ke telegram channel. Apabila ada perintah lain maka status tersebut berhenti mengirim. Dengan perintah /change kota yang akan dipantau sebelumya dapat diganti dengan kota yang diinginkan. Perintah /aqi digunakan untuk menampilkan status AQI dengan memasukkan nama kota yang akan dipantau. Perintah /list digunakan untuk menampilkan status terbaru AQI dari 15 kota yang terurutkan secara abjad.

Bot dapat mengirimkan pesan sekaligus ke beberapa pengguna dengan catatan harus diberi jeda minimal 0.1 detik/pesan/pengguna agar bot tersebut tidak dideteksi sebagai spam oleh sistem telegram.

Untuk tergabung ke channel pengguna telegram lainnya dapat melalui link https://t.me/raqm1, bergabung ke channel dan mengaktifkan notifikasi. Sumber data utama Bot ini berdasarkan data dari aqicn.org tetapi jika kota tersebut masuk wilayah Indonesia maka akan memilih yang dari iku.menlhk.go.id/aqms.

\section{Kesimpulan}

Kualitas udara di satu negara merupakan hal paling penting yang perlu diperhatikan karena manusia memerlukan oksigen untuk bisa terus hidup. Kualitas udara juga menjadi salah satu aspek penting majunya sistem di dalam negara tersebut. Pemanfaatan sistem pemantaauan kualitas udara dengan Semantic Web of Thing dimulai pengambilan data dari dua website berbeda dan menggabungkannya kemudian data tersebut dilakukan pemberian makna agar bisa memberikan informasi, pengetahuan baru dan data tersebut tidak membingungkan. Selanjutnya dipublikasikan melalui website dan media sosial telegram agar dapat diketahui oleh masyarakat luas.

Data kualitas udara ini juga dapat dimanfaatkan oleh pengembang lainnya untuk mengembangkan aplikasi mereka sendiri. Penyampaian kualitas udara melalui media sosial diharapkan dapat meningkatkan kepedulian masyarakat akan lingkungan sekitarnya. Meskipun masih banyak orang yang meremehkan, kini dampaknya sudah cukup bisa mengingatkan manusia untuk senantiasa menjaga bumi ini untuk tetap bersih dan asri.

\section{Referensi}

[1] G. K. Kang, J. Z. Gao, S. Chiao, S. Lu, and G. Xie, "Air Quality Prediction: Big Data and Machine Learning Approaches," Int. J. Environ. Sci. Dev., vol. 9, no. 1, pp. 8-16, 2018, doi: 10.18178/ijesd.2018.9.1.1066.

[2] T. H. E. Urban, R. Challenge, and O. F. The, "Meeting the MDG drinking target: The urban and rural challenge of the decade," World Heal. Organ., p. 47, 2006.

[3] P. R. Agarwal, "Semantic Web in Comparison to Web 2.0," in 2012 Third International Conference on Intelligent Systems Modelling and Simulation, 2012, pp. 558-563, doi: 10.1109/ISMS.2012.49.

[4] D. Naik, Umesha; Shivalingaiah, "Comparative Study of Web 1.0, Web 2.0 and Web 3.0," 6th Int. CALIBER 2008, Univ. Allahabad, Allahabad, no. August, 2014, doi: 10.13140/2.1.2287.2961.

[5] G. Abror, R. T. Widodo, and M. U. H. Al Rasyid, "Dynamic Sleep Scheduling on Air Pollution Levels Monitoring with Wireless Sensor Network," Emit. Int. J. Eng. Technol., vol. 5, no. 2, pp. 209-233, 2018, doi: 10.24003/emitter.v5i2.185.

[6] A. Sheth, C. Henson, and S. S. Sahoo, "Semantic sensor web," IEEE Internet Comput., vol. 12, no. 4, pp. 78-83, 2008, doi: 10.1109/MIC.2008.87.

[7] U. Al Rasyid, A. Sayfudin, A. Basofi, and A. Sudarsono, Development of semantic sensor web for monitoring environment conditions. 2016.

[8] A. J. Jara, A. C. Olivieri, Y. Bocchi, M. Jung, W. Kastner, and A. F. Skarmeta, "Semantic Web of things: An analysis of the application semantics for the loT moving towards the 
IoT convergence," Int. J. Web Grid Serv., vol. 10, no. 2-3, pp. 244-272, 2014, doi: 10.1504/ijwgs.2014.060260.

[9] K. Rodr, L. May, S. Inf, D. I. I. Pontif, and U. Cat, "From the sensor data streams to linked stream data. A survey of main approaches.," vol. 7, no. 2, pp. 1-11, 2014.

[10] M. U. H. A. Rasyid, I. Syarif, and I. A. H. Putra, "Linked data for air pollution monitoring," in 2017 International Electronics Symposium on Knowledge Creation and Intelligent Computing (IES-KCIC), 2017, pp. 65-70, doi: 10.1109/KCIC.2017.8228565.

[11] USEPA, "Technical Assistance Document for the Reporting of Daily Air Quality - the Air Quality Index ( AQI )," Environ. Prot., pp. 1-28, 2013. 